\title{
Analisa dan evaluasi rancang bangun insinerator sederhana dalam mengelola sampah rumah tangga
}

\author{
Fatkur Rhohman 1), dan M. Muslimim Ilham ${ }^{2)}$ \\ 1), 2)Prodi Teknik Mesin, Universitas Nusantara PGRI Kediri \\ E-mail: ${ }^{1)}$ fatkurrohman@unpkediri.ac.id, ${ }^{2)}$ im.muslimin@ @unpkediri.ac.id
}

\begin{abstract}
Abstrak
Penelitian ini bertujuan untuk menganalisa dan mengevaluasi pengelolaan sampah yang menggunakan insinerator sederhana. Tujuan awal pembuatan insinerator tersebut adalah untuk mengurangi tumpukan sampah rumah tangga di desa ABC. Dengan mempelajari model insinerator limbah B3 (Bahan berbahaya dan beracun) di rumah sakit, akhirnya penduduk dan akademisi berinisiatif untuk membuat insinerator sederhana. Namun dalam pelaksanaanya, ternyata ada beberapa hal yang menyebabkan proses pembakaran dalam insinerator tersebut tidak berjalan baik. Sehingga proses pengelolaan sampah dengan menggunakan insinerator tersebut tidak bisa menyelesaikan permasalahan sampah secara sempurna. Pada akhirnya, sampah-sampah tersebut menjadi gunungan sampah di tempat pembuangan sampah.
\end{abstract}

Kata Kunci: Evaluasi, Insinerator, Sampah,

\begin{abstract}
This study aims to analyze and evaluate waste management using simple incinerators. The initial purpose of making the incinerator was to reduce the household garbage in the $A B C$ village. By studying the model of B3 waste (hazardous and toxic materials) incinerators at the hospital, eventually the population and academics took the initiative to make a simple incinerator. However, in its implementation, it turns out that there are some things that have caused the combustion process in the incinerator to not work well. So that the process of managing waste using the incinerator cannot solve the garbage problem completely. In the end, the garbage becomes a mountain of garbage in a landfill.
\end{abstract}

Keywords:evaluate, Incinerator, Waste.

\section{PENDAHULUAN}

Masalah sampah semakin hari semakin memprihatinkan. Produksi sampah di indonesia pada tahun 2019 mencapai 66 - 67 juta ton. Dari jumlah tersebut, 60\% didominasi oleh sampah organik, sedangkan $15 \%$ didominasi oleh sampah plastik[1]. Atas peningkatan produksi sampah plastik yang meningkat tersebut, berbagai pihak dituntut untuk segera mengambil langkah nyata untuk menguranginya. Mulai dari pemerintah pusat hingga tingkat daerah diharapkan bisa mengambil bagian untuk menyelesaikan permasalahan sampah, khususnya sampah anorganik yang tidak bisa diurai secara alami. 
Faktor-faktor yang menjadikan sampah masalah penting, antara lain[2]:

a. Volume sampah sangat besar, sehingga melebihi kapasitas dan daya tampung tempat pembuangan akhir sampah (TPA). Rata-rata sampah yang dihasilkan perorang perhari adalah $0,5 \mathrm{~kg}$.

b. Lahan TPA tidak bisa diperluas karena tergeser tujuan penggunaan lain.

c. Teknologi pengolahan sampah tidak optimal sehingga sampah lambat pembusuk. Hal ini menyebabkan percepatan peningkatan volume sampah lebih besar dari pembusukannya. Oleh karena itu diperlukan perluasa areal TPA yang baru

d. Sampah yang sudah matang atau menjadi kompos tidak dikeluarkan dari TPA karena berbagai pertimbangan

e. Manajemem pengelolaan sampah tidak efektif sehingga sering kali menjadi penyebab distorsi dengan masyarakat setempat.

f. Pengelolaan sampah dirasakan tidak memberikan dampak positif kepada lingkungan

g. Kurang dukungan kebijakan dari pemerintah, terutama dalam memanfaatkan produk sampingan dari sampah, sehingga menyebabkan tertumpuknya produk tersebut di TPA

Penanganan masalah sampah tidak bisa satu per satu, namun harus terintegrasi. Yaitu dengan mengintegrasikan berbagai metode untuk berbagai fungsi dan luaran yang dihasilkan. Dari pemantauan yang telah dilakukan, menunjukkan bahwa sampah yang masuk terdiri atas 50\% kompos organik siap untuk dikompos, $10 \%$ sampah organik yang siap didaur ulang, 38\% campuran sampah organik-anorganik, dan $2 \%$ sampah tidak diolah seperti popok bayi[3].

Saat ini penerapan insinerator masih jarang dilakukan di indonesia. Pada umumnya, insinerator hanya digunakan untuk mengolah sampah medis yang tidak boleh dibuang sembarangan. Pengelolaan sampah akhir di Indonesia sebagian besar menerapkan metode reklamasi. Salah satu bagan tentang pengelolaan sampah yang terintegrasi adalah seperti berikut: 


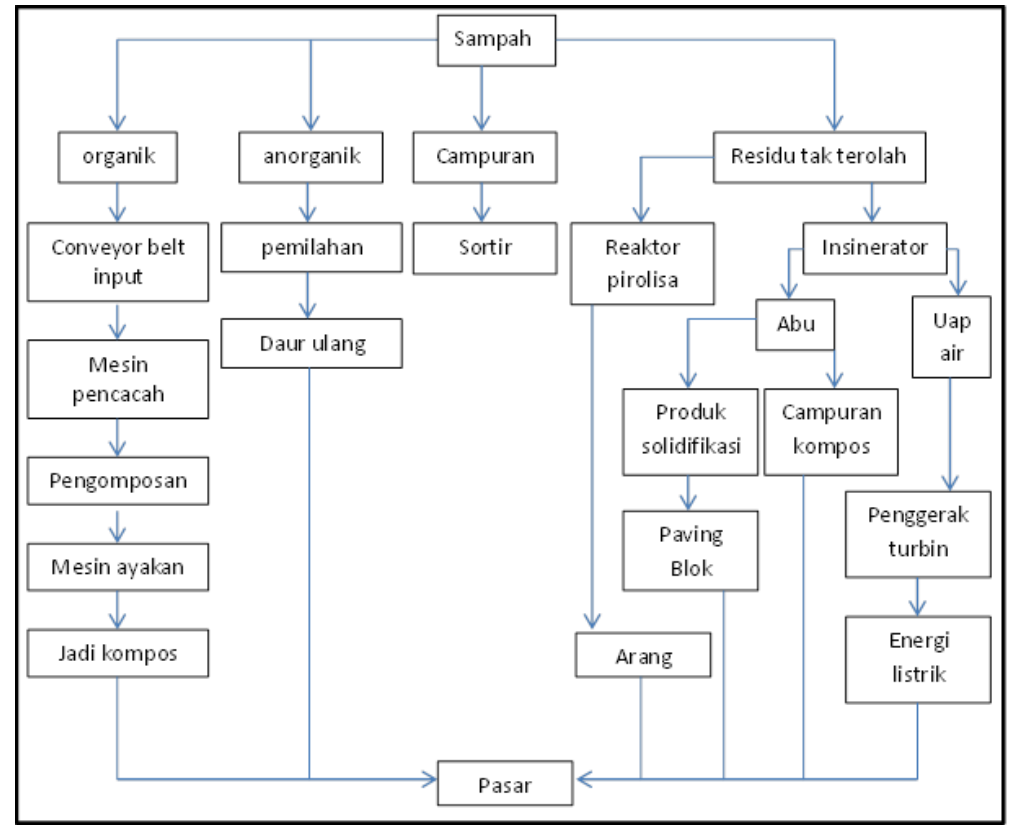

Gambar 1.Bagan tentang pengelolaan sampah yang terintegrasi[3].

Beberapa negara yang telah menggunakan incinerator antara lain : Jepang, Denmark, dan Swisterland. Ketiga negara tersebut penggunaan insineratornya mencapai 50\%. Sedangkan untuk negara lain seperti : Canada, USA, Australia, Finlandia, Prancis, dan banyak-banyak negara lain yang sudah menggunakan Insinerator dengan prosentase antara 10\% - 50\% [4].

Keuntungan dari pengolahan limbah dengan proses insinerasi adalah [5]:

a. Proses insinerasi dapat mengurangi volume dan berat limbah secara signifikan,

b. Limbah dapat ditangani dalam waktu yang relatif lebih singkat,

c. Area yang dibutuhkan relatif lebih kecil,

d. Pembuangan gas hasil pembakaran dapat dikontrol secara efektif untuk meminimumkan pengaruh pada lingkungan.

Pengolahan limbah dengan insenerator juga mempunyai beberapa kekurangan yaitu :

a. Modal awal yang cukup besar,

b. Biaya operasional cukup tinggi,

c. Masih memerlukan langkah-langkah lanjutan pada akhir proses (abu dan sisa pembakaran) di buang ke lahan lain.

Dari hasil penelitian yang dilakukan Utami, dkk. Kemampuan pembakaran Insinerator Rotary Kiln Termodifikasi dengan berat limbah medis $500 \mathrm{Kg}$ 
menghasilkan sisa pembakaran sebesar $21 \mathrm{Kg}$. Suhu pembakaran dan waktu pembakaran sangat berpengaruh pada pengoperasian insinerator karena semakin tinggi suhu pembakaran dan semakin lama waktu pembakaran menghasilkan residu abu yang sedikit dan kualitas abu serta kualitas asap paling baik[6]. Selain tipe rotary kiln, juga terdapat insinerator yang memiliki tipe reciprocating grate incinerator, maupun roller gate.

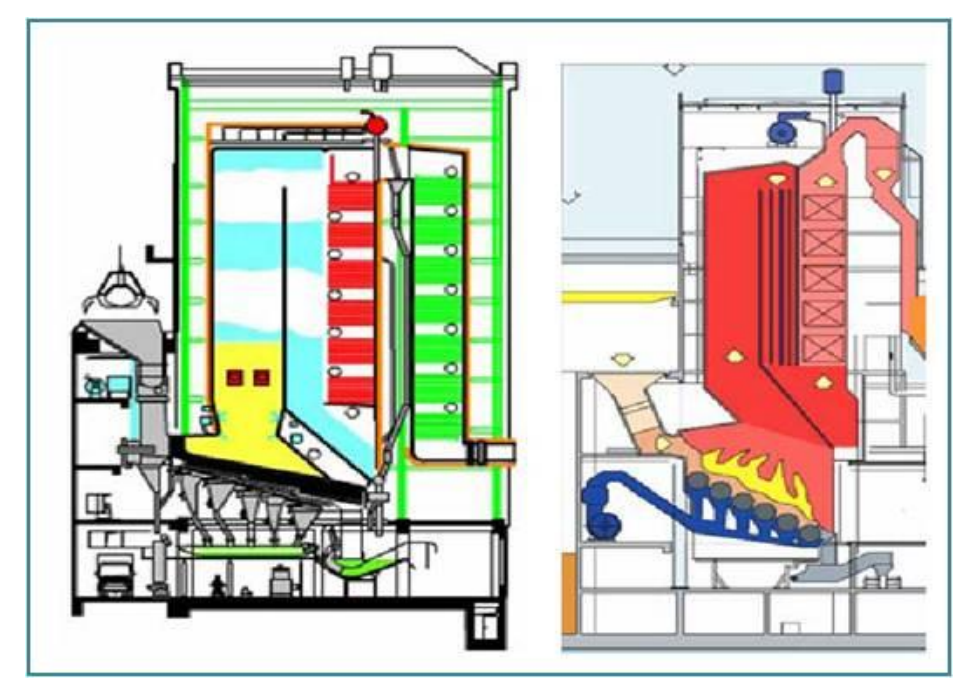

Gambar 2. Insinerator Reciprocating gate (Kiri) dan Roller gate (Kanan) [7].

\section{METODE PENELITIAN}

Metode penelitian yang digunakan adalah pengamatan langsung.Peneliti mengamati desain kerja insinerator, bagian-bagian insinerator dan fungsi perbagian pada insinerator untuk limbah B3 (Bahan Berbahaya dan Beracun). Dari hasil pengamatan tersebut, akan dilakukan pengembangan insinerator sederhana untuk proses pembakaran sampah rumah tangga. Untuk melihat hasil pengembangan insinerator sederhana, maka akan dilakukan uji coba selama beberapa waktu.

\section{HASIL DAN PEMBAHASAN}

Pada insinerator limbah B3 (Bahan Berbahaya dan Beracun), terdapat beberapa komponen yang utama. Dari gambar berikut, bisa dilihat bagian-bagian dan kegunaan dari bagian tersebut[8]. 


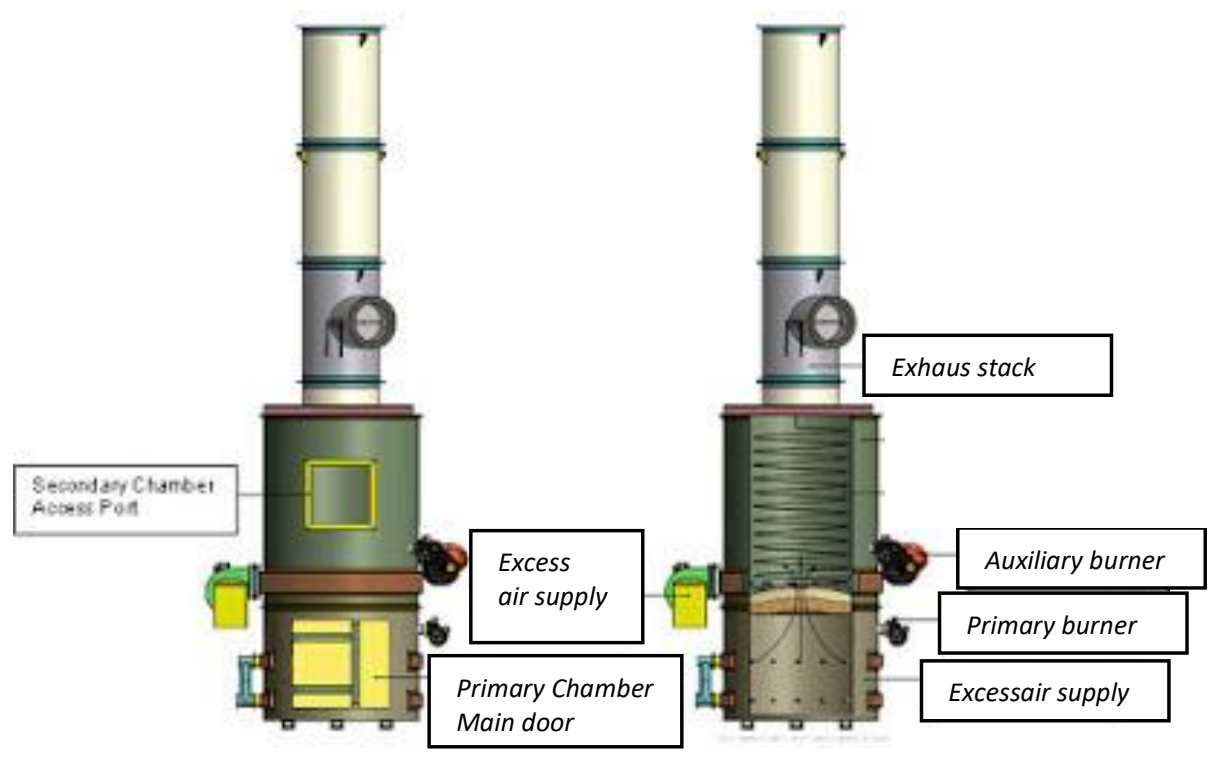

Gambar 3. Gambar insinerator dan bagian-bagiannya

Beberapa bagian dan kegunaan dari bagian-bagian tersebut antara lain:

a. Primary Chamber: ruang bakar utama dimana semua limbah atau sampah yang akan dibakar dimasukkan ke dalam primary chamaber ini.

b. Primary burner: Ini merupakan alat pembakar yang ada di dalam ruang bakar utama.

c. Excess air supply: Api tidak akan bisa menyala jika tidak ada udaranya, makanya dengan bantuan excess air supply udara dikirimkan ke dalam ruang bakar.

d. Auxiliary burner: ini berfungsi untuk pembakar pada ruangan yang kedua (atas)

e. Gasvortex: dalam ruangan ke 2 (atas) gas yang dihasilkan dari ruang pembakaran utama tadi di bikin berputar menyerupai cyclone.

Dari gambar insinerator tersebut, dapat dijelaskan cara kerja insinerator sebagai berikut:

a. Limbah yang akan dibakar dimasukkan ke dalam primary chamber melalui main door.

b. Didalam main chamber, sampah dibakar menggunakan primary burner.

c. Gas hasil pembakaran dari main chamber kemudian di bakar lagi dengan menggunakan auxiliary burner.

d. Kemudian gas yang dihasilkan dari auxiliary chamber tidak langsung di lepas ke udara bebas, harus diproses dulu dengan alat yang dinamakan wet scrabber, barulah dilepas ke udara bebas. Wet scrabber pada prinsipnya merupakan air 
yang dipercikkan, dan gas hasil pembakaran tadi dilewatkan di bawahnya.

Dari incinerator limbah B3 tersebut, akan dibuat model sederhana dang bisa menampung lebih besar dari yang sudah ada dipasaran. Bahan pembuatannya pun menggunakan bahan baku batu bata, semen, besi, dan pasir. Tujuan digunakan bahan-bahan tersebut karena pembuatannya lebih murah daripada menggunakan plat besi yang tebal. Desain yang akan dikembangkan pada intinya adalah memiliki 4 komponen utama, yaitu : Ruang bakar, saluran udara, pintu utama, cerobong asap, dan pintu abu.

Desain rancang bangun insinerator sederhana yang dikembangkan adalahsepertigambar di berikut:

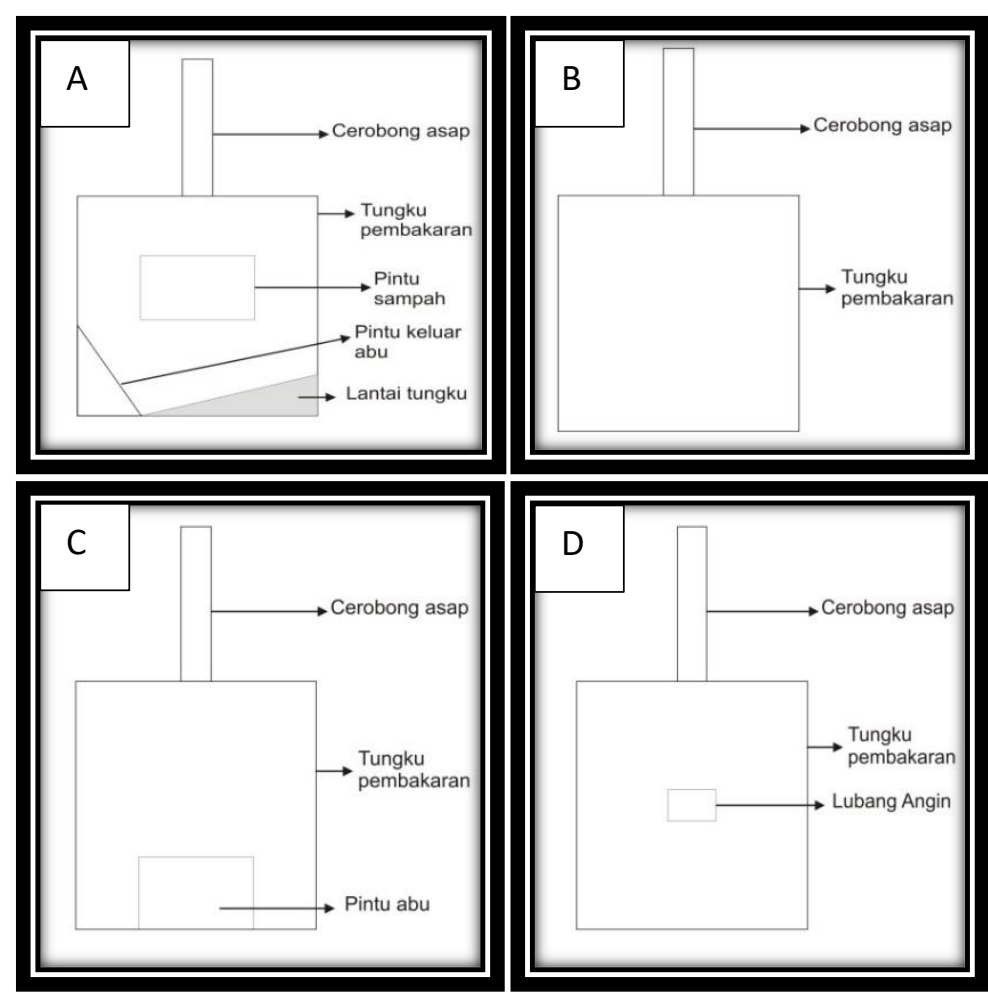

Gambar 4. Desain awal tungku insinerator (A) tampak depan, (B) tampak belakang, (C) tampak kanan, dan (D) tampak kiri

Bagian - bagian dari insinerator sederhana beserta kegunaannya antara lain:

a. Tungku pembakaran: adalah tempat terjadi proses pembakaran sampah.

b. Pintu Sampah : pintu untuk memasukkan sampah

c. Pintu abu : bertujuan untuk mempermudah proses pengeluaran abu sisa hasil pembakaran.

d. Lubang angin : Untuk membantu menambah suplai angin pada proses pembakaran 
e. Cerobong asap : saluran untuk mengeluarkan asap

Dari desain tersebut, dikembangkan insinerator sederhana seperti gambar berikut:

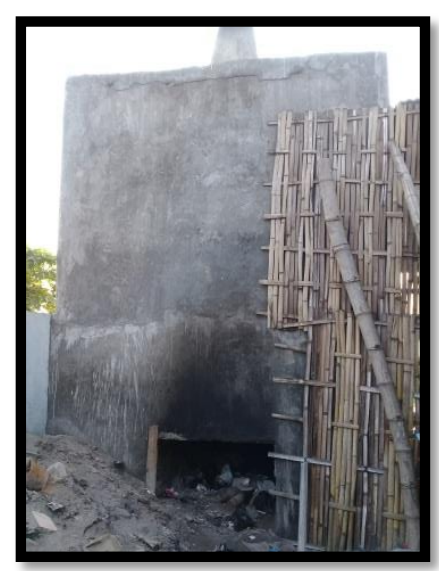

A

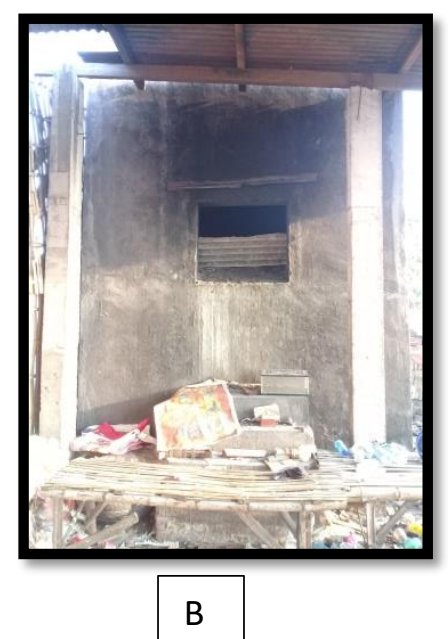

$\mathrm{B}$

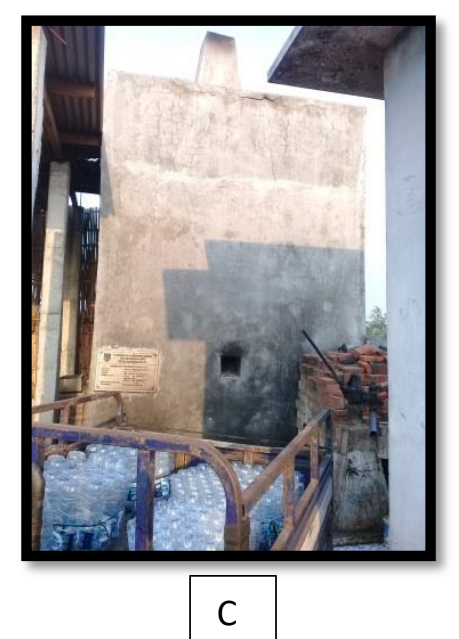

$\mathrm{C}$

Gambar 5. Insinerator sederhana (A) sisi kanan (B) sisi depan (C) sisi kiri

Proses kerja dari insinerator tersebut adalah sebagai berikut:

a. Sampah dimasukkan ke tungku pembakaran sampai batas yang sudah diberikan.

Namun biasanya sampah yang dimasukkan adalah sampah yang telah dipilihpilih oleh pemulung. Pemulung tersebut mengambil sampah yang sekiranya masih bisa dijual kembali ke pengepul sampah.

b. Sampah dibakar menggunakan burner melalui lubang masuk sampah. Pembakaran dilakukan beberapa menit sampai sampah bagian atas terbakar penuh.

c. Dalam satu kali proses pembakaran, sampah dibakar sampai habis. Jika sekiranya api mengecil, maka burner di nyalakan kembali.

d. Setelah sampah habis, abu sisa pembakaran dikeluarkan melalui pintu abu. Pintu tersebut diletakkan pada bagian paling bawah untuk memudahkan pengambilan abu sisa pembakaran. Lantai tungku pembakaranpun dibuat miring $15^{\circ}$ agar abu bisa keluar dengan lebih mudah. Pintu keluar abu juga diberikan besi melintang agar sampah tidak keluar (jatuh) saat terjadi proses pembakaran. Pemberian besi melintang tersebut juga membantu menambah suplai udara dari bawah tungku.

e. Setelah abu selesai dibersihkan, akan dilakukan proses pembakaran lagi.

Namun dalam proses pelaksanaanya, komposisi sampah yang bercampur aduk dan sebagian besar merupakan sampah basah menjadikan proses pembakaran dalam 
tungku insinerator menjadi lebih sulit dan lebih lama. Selain itu, campuran tanah dan pasir yang ikut terbuang, semakin mengurangi rongga-rongga udara yang dibutuhkan dalam tungku pembakaran. Hal lain yang menjadi masalah dalam TPS adalah kemampuan membakar sampah dalam insinerator tersebut lebih kecil dibandingkan dengan jumlah sampah yang dibuang oleh masyarakat ke TPS. Sehingga sampah-sampah yang tidak terbakar, menggunung di TPS menunggu antrian pembakaran.

Dari pengembangan insinerator sederhana pertama dan pelaksanaan pembakaran sampah, perlu ada evaluasi ulang tentang desain dari insinerator tersebut. Permasalahan yang timbul dari hasil pengamatan adalah antara lain:

a. Kurangnya suplai udara ke dalam tungku, akibatnya pada saat sampah sudah berada di bawah batas pengisian, api dari sampah yang terbakar lebih sering padam, jika dibandingkan dengan pada saat sampah masuk setinggi batas pengisian. Sehingga, pada saat sampah sudah di bawah batas pengisian, burner lebih sering digunakan untuk membantu proses pembakaran. Solusi dari permasalahan ini adalah penambahan lubang angin yang lebih rendah dari posisi sampah.

b. Kurang optimalnya proses pembakaran karena tercampurnya sampah basah dengan sampah kering. Sampah basah dan sampah kering tersebut seharusnya dipisahkan dahulu sebelum di masukkan ke dalam tungku pembakaran. Namun pengerjaan pemisahan tersebut akan membutuhkan waktu lebih lama. Solusi dari permasalahan ini adalah dengan dibuat tungku bertingkat. Tungku yang bawah bisa digunakan untuk sampah kering. Tungku yang bawah juga bisa digunakan untuk peletakan bahan bakar organik seperti kayu bakar, untuk membantu proses pembakaran. Sedangkan tungku yang atas digunakan untuk sampah basah agar bisa kering dahulu dari proses pembakaran di bawahnya.

c. Terlalu sempitnya pintu keluaran abu, sehingga untk mengeluarkan abu menjadi cukup susah. Solusi yang bisa ditawarkan adalah sengan memperbesar ukuran pintu keluaran abu tersebut.

d. Tidak ada tempat khusus untuk bantuan bahan bakar organik seperti kayu bakar, untuk membantu meningkatkan nyala api, sekaligus mengurangi penggunaan burner yang menggunakan bahan bakar minyak jenis solar. Solusi yang 
ditawarkan adalah dengan membangun insinerator tungku bertingkat.

\section{KESIMPULAN}

Dari hari pengamatan pembuatan insinerator sederhana tersebut, masih banyak kekurangan yang perlu untuk dibenahi. Beberapa kelemahan utama yang bisa diamati adalah kurangnya suplai udara, kurang optimalnya proses pembakaran di dalam tungku karena sampah yang tercampur, sempitnya pintu keluar abu, masih tingginya biaya operasional untuk membeli bahan bakar burner. Kelemahan tersebut harus diselesaikan dengan solusi yang sudah diberikan masing -masing. Tujuannya tidak lain adalah agar proses pembakaran dalam insinerator semakin optimal. Namun yang perlu ditekankan dalam pengembangan insinerator, bahwa insinerator bukan solusi utama untuk menyelesaikan masalah sampah. Insinerator hanyalah alat untuk memusnahkan sampah yang sudah ada. Solusi utama untuk menyelesaikan sampah tetap dengan menerapkan 3R (Reduce, Reuse, Recycle).

\section{DAFTAR PUSTAKA}

[1] E. Permana, "Indonesia Hasilkan 67 Juta Ton Sampah pada Tahun 2019," Www.Aa.Com.Tr, pp. 1-3,[Accessed: 08-Mar-2019].

[2] Sudrajat, Mengelola Sampah Kota. depok: Penebar Swadaya, 2006.

[3] K. Sejati, Pengolahan sampah terpadu dengan Sistem Node, Sub point, dan Center Point., 1st ed. Yogyakarta: Kanisius, 2009.

[4] T. Bagus, "Pengelolaan dan Pemanfaatan Sampah Menggunakan Teknologi Incenerator," J. Teknol. Lingkung., vol. 3, no. 1, pp. 17-23, 2002.

[5] A. M. R. Indah Nurhayati, "Pengolahan Limbah Bahan Berbahaya Dan Beracun (B3) Dengan Insinerator Tipe Reciprocating Grate Incinerator," vol. 3, no. 18, pp. 21-27, 1999.

[6] R. D. Utami, D. G. Okayadnya, and M. Mirwan, "Meningkatkan Kinerja Incenerator pada Pemusnahan Limbah Medis RSUD Dr. Soetomo Surabaya," $J$. Ilm. Tek. Lingkung., vol. 7, no. 2, pp. 115-123, 2011.

[7] Anonim, "Database of Waste Management Technologies," http://www.epem.gr. [Online]. Available: http://www.epem.gr/waste-c-control/database/html/WtE01.htm.
Fajar,"Bagaimana
Cara
Kerja
Incenerator,
"http://jualinceneratorrumahsakitblogspot.com, 2019. [online]. Available: http://jualineratorrumahsakit.blogspot.com/2016/08/cara-kerja incenerator.html.[Accessed: 11-Jul-2019]. 